\title{
Are medical ethicists out of touch? Practitioner attitudes in the US and UK towards decisions at the end of life
}

Donna L Dickenson Imperial College School of Medicine, London

\begin{abstract}
Objectives-To assess whether UK and US health care professionals share the views of medical ethicists about medical futility, withdrawing/withholding treatment, ordinary/extraordinary interventions, and the doctrine of double effect

Design, subjects and setting- $A$ 138-item attitudinal questionnaire completed by 469 UK nurses studying the Open University course on "Death and Dying" was compared with a similar questionnaire administered to 759 US nurses and 687 US doctors taking the Hastings Center course on "Decisions near the End of Life".

Results-Practitioners accept the relevance of concepts widely disparaged by bioethicists: double effect, medical futility, and the distinctions between heroiclordinary interventions and withholding/ withdrawing treatment. Within the UK nurses' group a "rationalist" axis of respondents who describe themselves as having "no religion" are closer to the bioethics consensus on withholding and withdrawing treatment.

Conclusions-Professionals' beliefs differ substantially from the recommendations of their professional bodies and from majority opinion in bioethics. Bioethicists should be cautious about assuming that their opinions will be readily accepted by practitioners.

(Fournal of Medical Ethics 2000;26:254-260)
\end{abstract}

Keywords: Death and dying; withdrawal of care; refusal of treatment

\section{Introduction}

For the past thirty years bioethicists' bread-andbutter has been critical examination of faulty thinking in biomedical practice. Where stereotypes and muddle prevailed, we have seen it as our task to bring philosophical clarity. On the face of it this is an admirable task, but some professional reputations have been built on clever hypotheticals with little relation to everyday practice. ${ }^{1}$ Furthermore, consequentialist approaches have tended to dominate, particularly in the area of death and dying.

For example, the President's Commission ${ }^{2}$ and other US official recommendations ${ }^{3}$ rejected the distinction between withholding and withdrawing treatment because they have the same effect. Similarly, clinicians who believe that there is a distinction (and that withdrawing treatment is more serious) might be less likely to initiate potentially useful treatments which they may later have to withdraw. Both these arguments are drawn from ethical consequentialism. By contrast, other approaches such as narrative ethics, ${ }^{4-7}$ hermeneutics, ${ }^{8}$ the ethics of care, ${ }^{9}$ or a power mode $l^{10}$ might view withdrawing care as different from withholding it: new relationships and expectations have been built up during the period in which care has been offered.

Likewise, the consensus in biomedical ethics has generally been against the distinction between ordinary and extraordinary treatment. Whereas extraordinary treatment can permissibly be forgone, in Catholic theology, ordinary treatment cannot. ${ }^{11}$ As stated by Cardinal Jean Villot, Vatican Secretary of State, in 1970, the same distinction applies to the doctor's duties as to the patient's:

"A medical man does not have to use all the techniques of survival offered him by a constantly creative science. In many cases, would it not be useless torture to impose vegetative resuscitation in the final stages of an incurable sickness?"12

However, what was extraordinary in 1970, when Cardinal Villot made his pronouncement, may now be ordinary. With the fluid boundary between what is technologically extraordinary one day and perfectly standard practice the next, there is some practical basis for scepticism about the distinction, but many writers in bioethics have concentrated on the philosophical incoherence of the contrast instead. ${ }^{13}$ Other once-standard distinctions which have come in for "demolition" include that between "active" and "passive" euthanasia ${ }^{14}$ and between relieving suffering versus shortening life, as in the doctrine of double effect. ${ }^{15}$

The concept of medical futility has been a particular focus of controversy. ${ }^{16}$ Because an underpinning definition of futility is crucial to decisions about withholding or stopping interventions, and because the greatest problem in American practice has often been seen as the tendency towards excessive interventions, futility has been a linchpin concept. Yet bioethicists have been suspicious of futility as merely a rationalisation, or as "too ambiguous and pejorative a term". ${ }^{17}$

Do doctors and nurses still use the concepts which many bioethicists have done their best to discredit? If so, do they do so out of ignorance, or is there a coherent pattern to their attitudes on decisions in death and dying-evidence, perhaps, of 
Table 1 Practitioner acceptance of the concepts of medical futility and extraordinary/ordinary treatments Percentage replying under each category and overall mean (UK nurses, with overall figure for US doctors and nurses in brackets) on a scale of 1 to 5 (1=strongly disagree, 5=strongly agree) to the following questions:

1. The distinction between extraordinary (or heroic) measures and ordinary treatments is helpful in making termination of treatment decisions.

2. Clinicians need better guidelines to help determine when treatments are medically futile.

3. Clinicians and patients (UK: dying people) generally agree about what constitutes medically futile treatment.

4. Clinicians are not required to provide medically futile treatment, even if a terminally ill patient or family member demands it.

\begin{tabular}{|c|c|c|c|c|c|c|}
\hline Question & $\begin{array}{l}1 \text { strongly } \\
\text { disagree }\end{array}$ & 2 & 3 & 4 & 5 strongly agree & Mean \\
\hline 1) Heroic distinction useful & $3 \%(4 \%)$ & $8 \%(7 \%)$ & $19 \%(19 \%)$ & $43 \%(31 \%)$ & $26 \%(39 \%)$ & $3.80(3.92)$ \\
\hline 2) Futility guidelines needed & $1 \%(4 \%)$ & $5 \%(7 \%)$ & $15 \%(19 \%)$ & $38 \%(32 \%)$ & $41 \%(39 \%)$ & $4.12(3.94)$ \\
\hline 3) Dying agree & $23 \%(18 \%)$ & $42 \%(33 \%)$ & $18 \%(28 \%)$ & $15 \%(17 \%)$ & $2 \%(5 \%)$ & $2.32(2.57)$ \\
\hline 4) Futile treatment not required & $5 \%(26 \%)$ & $13 \%(25 \%)$ & $27 \%(19 \%)$ & $37 \%(14 \%)$ & $17 \%(16 \%)$ & $3.48(2.67)$ \\
\hline
\end{tabular}

another sort of consensus than the bioethical one. In short, is bioethics in touch with what practitioners really think?

\section{Methods}

For an in-hospital ethics training programme on "Decisions near the end of life", the Hastings Center and the Education Development Center (EDC) developed a questionnaire on practitioners' attitudes towards ethical issues in death and dying, funded by the Kellogg Foundation. This "institutional profile" was piloted with 72 subjects and reviewed by an external panel of experts in clinical ethics, sociology, anthropology, health services research, psychology and statistics. A repeat survey was administered two months later $(n=52)$. Test reliability was estimated as good, using several different techniques. ${ }^{18}$ After this piloting process, the questionnaire was administered at five test hospitals ranging in size from 180 to 660 beds. The total numbers responding were 759 nurses and 687 doctors (369 internists, 174 surgeons, and 144 house officers).

For the Hastings Center, the primary purpose of the questionnaire was to "ground" the work which practitioners would be doing in their six-session training programme, by forcing them to define at the outset their own attitudes, values and ethical beliefs on such issues as withdrawing/withholding ventilation, artificial hydration and nutrition, and cardiopulmonary resuscitation. For the EDC the

Table 2 Awareness of Guidelines

Percentage replying "yes" to the question: Are you aware of any guidelines at your institution about the following: (US overall figures, with UK nurses in brackets)

Obtaining DNR orders

Documenting reasons for DNR order

Requests for organ donation

Recording patient's wishes in medical record

Obtaining informed consent

Determining patient capacity to participate in decisions

Withholding or stopping mechanical ventilation

Withholding or stopping artificial nutrition and hydration

How to proceed when ethical concerns about a patient's care arise prime interest was in compiling an expanding database reflecting current US practitioner attitudes towards issues around assisting death and letting die. ${ }^{19}$

A UK version of the questionnaire was developed by the author for an Open University course on "Death and Dying", again with both pedagogic and research objectives. Following a pilot run with 43 UK practitioners, the questionnaire was completed by 469 UK hospital and hospice nurses who were students on the Open University course between 1993 and 1997. (Although some questions from the US instrument were eliminated or redrafted to suit UK practice, the questions in the tables below used exactly the same wording, with three very minor exceptions [tables 1,2 and 9] in which the UK version appears in brackets.)

Completion of the questionnaire was optional on the Open University course, unlike the US counterpart, making numbers somewhat lower. In particular, there were too few doctors for statistical analysis. No UK doctors appear in the findings reported in this article, although findings concerning US doctors have been included for interest, and in some cases, for reporting comparisons between professions in the US.

The UK group includes a larger proportion of hospice nurses than the US sample, and therefore probably a higher exposure to critically or terminally ill patients. However, the US and UK nurse groups both encountered the questionnaire very early in their study, so that untutored responses are being measured. The nurse groups are also broadly comparable in terms of means for age (US $=39.5$, $\mathrm{UK}=38.0$ ) and number of years in the nursing profession (US=13.9, $\mathrm{UK}=15.6$ ).

Although further research is desirable to ascertain UK doctors' attitudes, UK nurses, of all British practitioner groups, may well give us the best idea of how relevant to terminal care are the concepts of double effect, futility and heroic/ordinary treatment. The US findings showed that nurses had the greatest amount of contact with dying people and surgical attending physicians the least. Nursing ethics, heavily influenced by the ethics of care, ${ }^{20}$ might also be particularly reluctant to accept the authority of the biomedical ethics establishment on such questions as withdrawing and withholding. 
Table 3 Sources of intra-staff conflict identified by UK nurses

How often do disagreements among staff arise over the following? $(1=$ almost never, $5=$ almost always) (mean and percentage answering either 3,4 or 5 )

Determination of patients' capacity to make decisions

$\begin{array}{ll}2.54 & 51.4 \%\end{array}$

informed consent process $\quad 2.45 \quad 48.8 \%$

Use of patients in research projects $\quad 1.96 \quad 30.9 \%$

How information is given to patients and families $\quad 2.63 \quad 55.6 \%$

$\begin{array}{lll}\text { Deciding when a treatment is medically futile } & 2.70 & 60.3 \%\end{array}$

What treatment alternative is best for a patient $\quad 2.69 \quad 58.4 \%$

When to consider the economic costs of a patient's care

$2.20 \quad 38.8 \%$

\section{Results and discussion}

1. MEDICAL FUTILITY AND EXTRAORDINARY TREATMENT

Question 1 of table 1 shows 69 per cent (UK nurses) and 70 per cent (US overall) agreeing or strongly agreeing that the distinction between extraordinary and ordinary treatment measures is useful, with 11 per cent in both countries disagreeing. (In fact this agreement prevails across all US professional groups: medical attending physicians mean 3.88, surgical attendings 4.06 , house officers 3.89 and nurses $4.02 .^{21}$ )

Consistent with this distinction, which implies that extraordinary measures are not required because they impose disproportionate burdens with minimal results, clinicians in both countries favour stronger guidelines on medical futility from professional bodies. (The survey was administered before the British Medical Association [BMA] guidelines on withdrawing and withholding treatment were published in September 1999.) This result on question 2 , table 1 , is interesting because awareness of existing guidelines is reasonably high in both national groups - although consistently higher in the US (table 2).

Item 3 of table 1 shows that 65 and 61 per cent of clinicians (UK and US respectively) disagree or disagree strongly with the statement that "Clinicians and dying people generally agree about what constitutes medically futile treatment". Only two and five per cent, respectively, strongly agree that they normally reach an accord with dying people and their families over whether to continue aggressive interventions. In question 4 of table $1, \mathrm{US}$ and UK practitioners disagree sharply over whether clinicians must provide medically futile treatment if dying people and their families demand it (although further research is necessary to determine the level of significance). This finding contrasts with practitioners' agreement on the "utility of futility": what to do once a treatment has been identified as futile is another matter. The American majority agree or strongly agree that clinicians are required to provide medically futile treatment requested by dying patients or their families. In contrast, 54 per cent of UK nurses agree or strongly agree that medically futile treatment is not obligatory even if patients and families disagree. (English law is generally loath to require doctors to act against their clinical judgment in providing futile treatment. ${ }^{22}$ ) United Kingdom nurses, however, report that futility causes more discord among clinical teams in the UK than any other issue, even expensive cardiopulmonary resuscitation (table 3 ).

\section{TREATMENT WITHDRAWAL}

The results so far show that practitioners in both the UK and the US rely heavily on the linked concepts of heroic/ordinary treatment and medical futility, although they may disagree on what to do when patients or their families request treatment which clinicians deem futile. Here practitioners disagree with the bioethics consensus, as they do on withholding and withdrawing treatment (table 4).

Very few US practitioners agree that "we give up on patients too soon", consistent with the finding that US doctors will continue offering treatment, even if they judge it medically futile, so long as patients and families want it. The incentive is to overtreat in a largely private system of health care provision $^{23}$ - posing particular problems for lastchance therapies and managed care. ${ }^{24}$ The UK sample contains a high proportion of hospice nurses, to whom the notion of treatment-at-allcosts is likely to be anathema. Palliative care is not seen as treatment withdrawal in hospice philosophy, and aggressive interventions are rejected in favour of a holistic approach to death and dying.

Table 5 suggests that UK nurses are the most likely to disagree with accepted bioethical wisdom: only one in five agrees or agrees strongly that withholding and stopping treatment are the same in ethical terms. Over three in five, 62 per cent, disagree or disagree strongly with the statement. Overall only US medical attending physicians are as likely to agree as disagree that there is no ethical difference. Every other group is more likely to disagree than agree with the "official" view, ie the BMA

Table 4 Undertreatment and overtreatment in UK and US practice

On a scale where $1=$ strongly disagree and $5=$ strongly agree, to what degree do you agree or disagree with the following statements: 1. Sometimes I feel the treatments I offer my patients are overly burdensome.

2. Sometimes I feel we give up on patients too soon.

\begin{tabular}{|c|c|c|c|c|c|}
\hline & UK nurses & US internists & $\begin{array}{l}\text { US medical } \\
\text { attendings }\end{array}$ & US house officers & US nurses \\
\hline 1. Treatment burdensome & $3.31(52 \%)$ & $3.43(58 \%)$ & $3.02(45 \%)$ & $4.01(78 \%)$ & $3.34(51 \%)$ \\
\hline 2. Give up too soon & $2.33(20 \%)$ & $2.22(15 \%)$ & $1.84(7 \%)$ & $2.05(8 \%)$ & $2.10(12 \%)$ \\
\hline
\end{tabular}

For items 1 and 2, differences by profession and nationality are significant at $\mathrm{p}<0.0001$ (one-way analysis of variance). 
Table 5 Is withdrawing treatment ethically different from never starting it?

Percentage agreeing or strongly agreeing with the statement "There is no ethical difference between withholding (not starting) a life support measure and stopping it once it has been started", with mean score (in parentheses), on scale of 1 to 5 ( $1=$ strongly disagree, $5=$ strongly agree)

\begin{tabular}{llllll}
\hline UK nurses & US medical attendings & US surgical attendings & US house officers & US nurses & US overall \\
\hline $20 \%(2.39)$ & $43 \%(3.00)$ & $38 \%(2.84)$ & $44 \%(2.96)$ & $27 \%(2.49)$ & $34 \%(2.71)$ \\
\hline
\end{tabular}

Table 6 Practitioner agreement with the doctrine of double effect

Percentage agreeing or strongly agreeing with the statement: "Sometimes it is appropriate to give pain medication to relieve suffering, even if it may hasten a patient's death" with mean score (in parentheses), on scale of 1 to 5 (1=strongly disagree, 5=strongly agree).

\begin{tabular}{llllll}
\hline UK nurses & US medical attendings & US surgical attendings & US house officers & US nurses & US overall \\
\hline $94 \%(4.67)$ & $94 \%(4.55)$ & $92 \%(4.52)$ & $92 \%(4.56)$ & $86 \%(4.35)$ & $89 \%(4.44)$ \\
\hline
\end{tabular}

guidelines of September 1999 (see references 2 and 3 for US).

\section{DOUBLE EFFECT AND EUTHANASIA}

Some bioethicists, and most supporters of euthanasia, regard the doctrine of double effect as a hypocritical remnant of Catholic moral theology ${ }^{25}{ }^{26}$; but it is accepted by many practitioners. In England the High Court clarified in the 1997 case of Annie Lindsell that existing law could accommodate a general practitioner's willingness, at the request of a woman dying of motor neurone disease, to prescribe analgesic medication in quantities that might have the effect of shortening her life. As table 6 indicates, this judgment confirms what many practitioners already believe.

Only three per cent of UK nurses disagreed or strongly disagreed with this statement. The great majority reject the argument (made by the Voluntary Euthanasia Society in the 1994 hearings before the House of Lords Select Committee on Euthanasia) that it is hypocritical to give analgesics in the knowledge that the patient's death may result, while claiming only to be concerned with pain relief. Likewise, practitioners largely accept the distinction between "passive" and "active" euthanasia, distrusted by many bioethicists, to the extent that they see an important moral distinction between stopping treatment and assisting suicide. ${ }^{27}$ Although the consequences of the two actions may be the same, seven out of eight practitioners surveyed, across countries and professions, agree or strongly agree that the content of the actions is ethically different (table 7 ).

Junior doctors in the US are most likely to agree with this statement, and US nurses most likely to disagree, although only 11 per cent of the latter disagreed or strongly disagreed with the statement. It is often said that nurses are more unwilling to see treatment stopped than doctors, because they are more intimately involved in patient care. In the case of the persistent vegetative state (PVS) patient Tony Bland, for example, nurses initially opposed the decision by the family and consultant to withdraw artificial nutrition and hydration. ${ }^{28}$ But both nurses and doctors surveyed reject the argument that because the consequences of treatment withdrawal and assisted suicide are the same, there is no ethical distinction. When the question of disconnecting feeding tubes is tackled more explicitly, a slightly diminished majority of practitioners still uphold the distinction between that and euthanasia, as table 8 indicates.

\section{PATIENT PARTICIPATION AND PRACTITIONER} SATISFACTION

On attitudes towards patient autonomy and participation in decision making, UK nurses demonstrate a greater commitment than any of the US groups, as shown in table 9, particularly questions 1 and 2 . (Note that a high score on question 1 indicates strong commitment to letting the patient decide,

Table 7 Practitioner agreement with distinction between withholding treatment and assisting suicide

Percentage agreeing or strongly agreeing with the statement: "To allow patients to die by forgoing or stopping treatment is ethically different from assisting in their suicide", with mean score (in parentheses), on scale of 1 to 5 ( $1=$ strongly disagree, $5=$ strongly agree).

\begin{tabular}{llllll}
\hline UK nurses & US medical attendings & US surgical attendings & US house officers & US nurses & US overall \\
\hline $87 \%(4.22)$ & $89 \%(4.47)$ & $86 \%(4.44)$ & $94 \%(4.57)$ & $85 \%(4.33)$ & $87 \%(4.41)$ \\
\hline
\end{tabular}

Table 8 Practitioner agreement with the statement: "Disconnecting a feeding tube is killing a patient"

Percentage agreeing or strongly agreeing with statement, on scale of $1=$ strongly disagree, $5=$ strongly agree, with mean score in parentheses.

\begin{tabular}{llllll}
\hline UK nurses & US medical attendings & US surgical attendings & US house officers & US nurses & US overall \\
\hline $18 \%(2.22)$ & $11 \%(1.84)$ & $12 \%(1.89)$ & $9 \%(1.62)$ & $12 \%(1.97)$ & $12 \%(1.89)$ \\
\hline
\end{tabular}


Table 9 Attitudes about patient involvement in decision making at the end of life Extent of agreement or disagreement with the following statements (1=strongly disagree, $5=$ strongly agree) (mean and percentage answering 4 or 5 )

\begin{tabular}{|c|c|c|c|c|c|c|}
\hline & UK nurses & US medical attendings & US surgeons & US house officers & US nurses & US overall \\
\hline 1. & $4.55(93 \%)$ & $4.39(86 \%)$ & $4.44(87 \%)$ & $4.49(87 \%)$ & $4.52(89 \%)$ & $4.48(87 \%)$ \\
\hline 2. & $2.74(28 \%)$ & $3.47(56 \%)$ & $3.70(65 \%)$ & $3.55(59 \%)$ & $3.31(50 \%)$ & $3.42(54 \%)$ \\
\hline 3. & $2.44(16.5 \%)$ & $2.68(29 \%)$ & $2.95(35 \%)$ & $2.18(29 \%)$ & $2.38(19 \%)$ & $2.51(23 \%)$ \\
\hline
\end{tabular}

1. All competent patients, even if they are not considered terminally ill, have the right to refuse life support, even if that refusal may lead to death.

2. Many patients perfer to let their caregiver make the decision about what treatment is best.

3. Many patients prefer not to know they are dying.

Table 10 Satisfaction with patient involvement in practice (mean and percentage answering 4 or 5)

\begin{tabular}{|c|c|c|c|c|c|c|}
\hline & UK nurses & $\begin{array}{l}\text { US medical } \\
\text { attendings }\end{array}$ & US surgeons & US house officers & US nurses & US overall \\
\hline 1. Patients informed & $3.11(44 \%)$ & $3.40(49 \%)$ & $3.51(50 \%)$ & $3.23(43 \%)$ & $2.75(25 \%)$ & $3.04(35 \%)$ \\
\hline 2. Patients grasp what told & $3.12(43 \%)$ & $3.32(42 \%)$ & $3.46(49 \%)$ & $3.22(39 \%)$ & $2.80(26 \%)$ & $3.05(35 \%)$ \\
\hline 3. Patients get help to choose & $3.05(40 \%)$ & $3.29(43 \%)$ & $3.38(44 \%)$ & $3.08(35 \%)$ & $2.77(26 \%)$ & $3.00(33 \%)$ \\
\hline 4. Staff find out patients' wishes & $3.31(51 \%)$ & $3.22(40 \%)$ & $3.32(39 \%)$ & $2.91(27 \%)$ & $2.79(26 \%)$ & $2.97(31 \%)$ \\
\hline 5. Wishes recorded & $3.43(56 \%)$ & $3.17(37 \%)$ & $3.19(36 \%)$ & $3.19(37 \%)$ & $2.61(21 \%)$ & $2.88(29 \%)$ \\
\hline 6. Ethical issues discussed & $3.02(41 \%)$ & $3.16(39 \%)$ & $3.07(31 \%)$ & $2.99(31 \%)$ & $2.69(26 \%)$ & $2.88(31 \%)$ \\
\hline
\end{tabular}

(Differences by profession and nationality significant at $p<.0001$, one-way analysis of variance)

On a scale where $1=$ not very satisfied and $5=$ very satisfied: at your workplace, how satisfied are you about the extent to which:

1. Patients are informed of different care alternatives.

2. Patients understand the information they are told about their condition and treatment alternatives.

3. Patients get the help they need to make decisions about care alternatives.

4. Staff find out what critically and terminally ill patients want.

5. Patients' wishes are recorded in the medical (UK: and nursing) record

6. Ethical issues in a patient's care are discussed by staff.

whereas the opposite is true on questions 2 and 3.) Yet as table 10 demonstrates, they are also considerably more satisfied with the extent to which these rights are respected in clinical practice. I have explored this interesting and unexpected juxtaposition in greater detail elsewhere ${ }^{29}$ and only wish to repeat one point here. The authors of the American survey, Solomon et al, were puzzled that US practitioners were very dissatisfied with the care received by terminally ill patients, but disagreed with professional bodies' recommendations. United Kingdom nurses, like their US medical and nursing colleagues, disagree with such recommendations: they believe that withdrawing care is different from withholding it, and they think futility is a meaningful concept. However, UK nurses are much happier with practice in terminal care (table 10). This suggests that there is no connection between satisfaction or dissatisfaction with patient care and disagreement with the bioethics consensus.

\section{RATIONALISM, RELIGION AND ATTITUDES}

TOWARDS NATIONAL GUIDELINES

A substantial number of UK nurses surveyed describe themselves as having "no religion". This group, whom I call "rationalists", ${ }^{30}$ shows a statistically significant degree of scepticism about the distinction between withholding and withdrawing treatment, but not about the doctrine of double effect concerning unintentionally hastening death (table 11). Although double effect is originally a Catholic doctrine, UK nurses of all religions, and of no religion, accept it. In fact practitioners who have no religion actually accept it slightly more strongly and more consistently (having a lower standard deviation). This is probably because they have fewer qualms about intentionally hastening death than the other two groups. On the other two questions, the "rationalist" minority does hold views which are significantly different. They are far more likely to agree (with the professional bodies' consensus) that there is no difference between withdrawing treatment once started and not offering it in the first place. And they are much more sympathetic to assisted suicide, a difference significant at the .0001 level.

This table offers us a suggestive answer to the question of why practitioners' attitudes are intractable to persuasion by national recommendations: these attitudes could correlate with religious belief - or lack of it. Academic ethicists are likely to be rationalists themselves; others like Tristram Engelhardt, himself an active church member, are concerned to develop a common core of principles on which believers and non-believers could all agree. ${ }^{31}$ Does the secular orientation of modern bioethics help to account for the distance between the bioethical consensus and practitioners' beliefs?

\section{Conclusions}

Whether practitioners do accept doctrines and concepts widely disparaged by bioethicists says nothing, of course, about whether they should accept them. To argue otherwise is to fall prey to the naturalistic fallacy. ${ }^{32}$ Solomon et al generally assumed that practitioners should not distinguish between withdrawing and withholding care, in the face of national commission recommendations to 
Table 11 Reported religious belief compared with position on withholding/withdrawing treatment, double effect and assisted suicide, $U K$ nurses (1 = strongly disagree, $5=$ strongly agree)

Mean scores on scale of 1 to 5 (1=strongly disagree, $5=$ strongly agree) with standard deviation in parentheses

Two-sample t-test with equal variances for combined Protestant/Catholic groups compared with "no religion" group

\begin{tabular}{llll}
\hline Statement & $\begin{array}{l}\text { Protestant or } \\
\text { Catholic (n=373) }\end{array}$ & $\begin{array}{l}\text { No religion } \\
(n=62)\end{array}$ & Significance \\
\hline $\begin{array}{l}\text { 1. There is no ethical difference between withholding (not starting) a life } \\
\text { support measure and stopping it once it has been started. }\end{array}$ & $2.30(1.16)$ & $2.81(1.32)$ & $\mathrm{P}<.002$ \\
$\begin{array}{l}\text { 2. Sometimes it is appropriate to give pain medication to relieve suffering, } \\
\text { even if it may hasten a patient's death. }\end{array}$ & $4.67(.76)$ & $4.76(.59)$ & $\mathrm{P}<.386$ \\
$\begin{array}{l}\text { 3. Although it may be illegal, it it not always unethical to hasten a patient's } \\
\text { death upon his or her request. }\end{array}$ & $3.00(1.29)$ & $3.77(1.32)$ & $\mathrm{P}<.0001$ \\
\hline
\end{tabular}

NB There were no respondents who described themselves as Jewish or Muslim; numbers of Hindu and Buddhist respondents were too small for analysis.

the contrary. If implemented, Solomon et al felt, the official bodies' directives would undermine the "technological imperative" of overtreatment and aggressive intervention at the end of life. But even though US practitioners generally agreed that dying patients were more likely to be overtreated than abandoned too soon, they had not accepted the corollary attitudes that would weaken the grip of the technological imperative. For example, they were loath to withdraw care once started, because they felt that stopping treatment was more serious than withholding it in the first place.

One solution proposed by Solomon et al was that bioethicists should step up their efforts to educate practitioners about national guidelines. ${ }^{33}$ Solomon and her colleagues often appear to accept scientific positivism ${ }^{34}$ : bioethics comes across as an activity in which specialists make scientifically validated advances and practitioners accept them. I want to argue the other way around: practitioners can educate us, and empirical evidence about what they really think can add maturing sophistication to the traditional analytical concerns of bioethics. ${ }^{35}$ Medical ethics risks becoming a self-regarding activity if it does not incorporate what practitioners think and do. This is certainly not to say that we should slavishly follow practitioner opinion when we know it to be fuzzy thinking; but neither should we condemn practitioner opinion as misguided. Nor should we try to reduce medical ethics to a positivistic model which we, in our wisdom, can then hand on to clinicians.

Medical ethicists who espouse an a priori model of decision making, such as principlists, are more likely to think that practitioners are just plain wrong if they persist in opinions which contradict the collective wisdom of bioethicists. If ethical decision making is a matter of coherent a priori reasoning, then there is no reason to expect practitioners to excel at what they were never trained to do, and every reason to believe that philosophers will make a better job of it. Conversely, if the facts of actual cases make a difference, and if an empirical model of decision making is preferred, then practitioners can be expected to know something which philosophers do not. If they disagree with national recommendations, that does not necessarily mean that they are ethically ignorant. Although practitioners do show a degree of ignorance of national guidelines, that does not explain all the disparity between their beliefs and the bioethics consensus. Perhaps, to paraphrase Thoreau, they simply march to the beat of a different drummer.

We need to know more about why practitioners differ from bioethicists, and from each other, in their attitudes towards decisions near the end of life. These findings are preliminary: further research is required to ascertain levels of significance for comparisons between US and UK practitioners, and to measure the attitudes of UK doctors. Yet wanting to know more is an important first step: it implies that practitioners' attitudes are not merely misguided, but may reflect alternative and equally valid models. One such alternative model of medical ethics is rooted in phronesis, the Aristotelian concept of the skills of practical judgment. ${ }^{5}$ We would expect practitioners to have particular skills in practical judgment, and to have something to teach us. Whether or not we bioethicists want to accept that particular model, we should at least be sensitive to the possibility that we are indeed out of touch.

\section{Acknowledgements}

The author gratefully acknowledges the assistance of Bruce Jennings of the Hastings Center; Vivian Guilfoy, Karen Heller, Mildred Solomon and Lydia O'Donnell of the Education Development Center, Newton, Massachusetts; and Deborah Ridout of the Imperial College statistical consultation service.

Donna L Dickenson is Leverhulme Reader in Medical Ethics and Law, Imperial College School of Medicine, London. Address for correspondence: Medical Ethics Unit, Department of Primary Healthcare and General Practice, Imperial College School of Medicine, Norfolk Place, London W2 1PG, UK.

\section{References and notes}

1 Wilkes KV. Real people: personal identity without thought experiments. Oxford: Clarendon Press, 1988.

2 President's Commission for the Study of Ethical Problems in Medicine and Biomedical and Behavioural Research. Deciding to forgo life-sustaining treatment: ethical, medical and legal issues in to forgo life-sustaining treatment: ethical, medical and legal issues in tor the Study of . Washington DC. President's Commission for the Study of Ethical Problem

3 See, for example: Stanley JM, ed. The Appleton consensus: suggested international guidelines for decisions to forgo medical treatsuggested international guidelines for decisions to forgo medical treat-
ment. Appleton, Wisconsin: Lawrence University, 1992 and 
also fournal of Medical Ethics 1989;15:129-36. The Hastings Center. Guidelines on the termination of life-sustaining treatment and the care of the dying. Bloomington and Indianapolis: Indian University Press, 1987. On page 130 the Guidelines also argue in terms of patient autonomy, which would be violated if doctors always felt an obligation to continue with treatment once initiated, even if the patient changed her mind.

4 Rosenstand N. The moral of the story: an introduction to ethics [2nd ed].Mountain View, California: Mayfield Publishing, 1997.

5 Levine P. Living without philosophy: on narrative, rhetoric and morality. Albany: State University of New York Press, 1998.

6 Nelson HL, ed. Stories and their limits: narrative approaches to biothics. London: Routledge, 1997.

7 Newton AZ. Narrative ethics. Cambridge, Massachusetts: Harvard University Press, 1995.

8 Widdershoven G. Discussing cases in clinical ethics: ethical problem-solving, moral phenomenology or hermeneutic dialogue? Bulletin of the European Society for Philosophy of Medicine in Healthcare 1995;3:4. Widdershoven G, Smits MJ. Ethics and narrative. In: Josselson R, ed. The narrative study of lives. Thousand Oaks, California: Sage, 1996:4:275-87.

9 Noddings N. Caring: a feminine approach to ethics and moral edu cation. Berkeley: University of California Press, 1984. Held V. Feminist morality: transforming culture, society and politic Chicago: University of Chicago Press, 1993. Bowden P. Caring: gender-sensitive ethics. London: Routledge, 1997.

10 Brody HA. The healer's power. New Haven: Yale University Press: New Haven, 1992.

11 Gillon R. Philosophical medical ethics. Chichester: John Wiley, 1986: 138.

12 Cited in Maguire DC. A Catholic view of mercy killing. In: Kohl M, ed. Beneficent euthanasia. Buffalo, New York: Prometheus Books, 1975: 75

13 Brock DW. Death and dying. In: Life and death: philosophical essays in biomedical ethics. Cambridge: Cambridge University Press, 1993: $167 \mathrm{ff}$.

14 Rachels JA. The end of life: euthanasia and morality. Oxford: Oxford University Press, 1986

15 Glover J. Causing death and saving lives. Harmondsworth: Penguin, 1977: ch 6: Ends and means: double effect.

16 Among many other sources, see: fournal of Medicine and Philosophy 1995;20:2. Zucker MB, Zucker HD, eds. Medical futility and the evaluation of life-sustaining interventions. Cambridge: Cambridge University Press, 1997. Jecker N, Schneiderman I. Wrong medicine: doctors, patients and futile medicine. Baltimore: Johns Hopkins Press, 1995. Halliday R. Medical futility and the social context. Fournal of Medical Ethics 1997;23:148-53. Hilberman M, Kutner J, Parsons D, Murphy DJ. Marginally effective medical care: ethical analysis of issues in cardiopul. monary
17 Gillon R. Futility and medical ethics [editorial]. Fournal of Medical Ethics 1997;23: 339-40.

18 O'Donnell L, et al. Provider satisfaction with treatment decisions near the end of life. Health Services Research 1992;22: 340-51.

19 Solomon MZ, O'Donnell L, Jennings B, Guilfoy V, Wolf SM, Nolan K. Decisions near the end of life: professional views on life-sustaining treatments. American Fournal of Public Health 1993;83:14-23.

20 Dalley G. Ideologies of caring. Basingstoke: Macmillan, 1980. Hanford L. Nursing and the concept of care: an appraisal of Noddings' theory. In: Hunt G, ed. Ethical issues in nursing. London: Routledge, 1994. Allmark P. Can there be an ethics of care? Fournal of Medical Ethics 1995;21:19-24. Bradshaw A. Yes! There is an ethics of care: an answer for Peter Allmark. Fournal of Medical Ethics 1996;22:8-12.

21 See reference 19: table 4.

$22 \operatorname{Re} \mathcal{F}[1990] 3$ All England Reports 930.

23 Gunderman R. Medicine and the pursuit of wealth. Hastings Center Report 1998;1:8-13.

24 Daniels N, Sabin JE. Last chance therapies and managed care. Hastings Center Report 1998;2:27-41.

25 Institute of Medical Ethics Working Party on the Ethics of Prolonging Life and Assisting Death. Assisted death. Lancet 1990; 336:610-13.

26 Kuhse H, Singer P. Should the baby live? The problem of handicapped infants. Oxford: Oxford University Press, 1985.

27 Hopkins PD. Why does removing machines count as "passive" euthanasia? Hastings Center Report 1997;27:29-37.

28 Airedale NHS Trust $v$. Bland [1993] 1 All England Reports 821.

29 Dickenson D. Practitioners' attitudes towards ethical issues at the end of life: is the UK actually more autonomy-minded than the US? Fournal of Palliative Care 1999;15:57-63.

30 In sense (3) as used by Flew: The rejection of religious belief as being without rational foundation. In: Flew A, ed. A dictionary of philosophy. London: Pan, 1979: 278.

31 Engelhardt T. The foundations of bioethics. Oxford: Oxford University Press, 1997.

32 "The mistake ... of deducing conclusions about what ought to be from premises that state only what is the case: or the other way about". First labelled by G E Moore in Principia ethica, 1903, edited by Thomas Baldwin. Cambridge: Cambridge University Press, 1994. See also: reference 30: 223 .

33 See reference 19: 15.

34 Halfpenny P. Positivism. In: Miller D, Coleman J, Connelly W, Ryan A, eds. The Blackwell encyclopaedia of political thought. Oxford: Blackwell Publishers, 1987: 395.

35 Hope T. Empirical medical ethics. Fournal of Medical Ethics 1999;25:319-20. 